\title{
AS EXPRESSÕES DA SINGULARIDADE E AS CATEGORIZAÇÕES UNIVERSAIS
}

\author{
The Expressions of Singularity and the Universal Categorization
}

Las Expresiónes de la Singularidad y las Categorizaciónes Universales

Ana Maria Lopez Calvo de Feijoo

Myriam Moreira Protasio

\begin{abstract}
Resumo: "As expressões da singularidade e as categorizações universais" tem como proposta colocar em discussão as categorizações de diferentes modos de expressão do homem, onde ocorre um abandono das diferenças humanas decorrentes das suas singularidades. Pretende-se, ainda, valorizar o singular em detrimento ao universal, através de dois personagens kierkegaardianos, descritos pelo filósofo de forma ricamente detalhada, permitindo assim dar destaque à singularidade de cada um.

Palavras-chave: Singularidade; Universalidade; Filosofia existencial.
\end{abstract}

\begin{abstract}
The expressions of singularity and the universal categorization" has the purpose of addressing the categorization of different forms of human expression, where an abandonment of recognition of human differences occurs, as a result of singularity. In addition, it is intended that singularity be recognized in deficit of the universal, by means of two kierkegaardian characters, which were described by the philosopher in great detail, thus allowing for the acknowledgement of singularity of every individual.

Keywords: Singularity; Universality; Existential philosophy.

Resumen: "Las expresiones de la singularidad y las categorizaciones universales" tienen como propuesta colocar en discusión las categorizaciones de los diferentes modos de expresión del hombre, donde ocurre un abandono de las diferencias humanas provenientes de sus singularidades. Se pretende todavía, valorizar lo singular en detrimento de lo universal, a través de dos personajes kierkegaardianos, descritos por el filósofo de forma ricamente detallada, permitiendo así destacar la singularidad de cada uno.

Palabras-clave: Singularidad; Universalidad; Filosofía existencial.
\end{abstract}

\section{Introdução}

Na psiquiatria tradicional, comumente categoriza-se todo comportamento humano que se desvie de um padrão estabelecido pela ordem médica vigente. Essa padronização consta em manuais descritivos através dos quais se pode fazer a comparação entre os sintomas apresentados pelo indivíduo singular e aqueles descritos nos manuais (CID-10). A conclusão acerca da categoria diagnóstica em que um dado indivíduo se insere é feita de forma quantitativa, de acordo com certo número de sintomas apresentados entre aqueles descritos em determinado "Transtorno" constante de tais manuais.

Com tais critérios de diagnóstico, a singularidade torna-se secundária ao universal. O universal passa a determinar o singular e, dessa forma, esse deixa de existir, passando-se apenas a enxergar a categoria à qual uma determinada pessoa pertence. Relacionar-se com o indivíduo enquanto categoria implica no abandono do homem e tomá-lo como um objeto passível de mensuração e manipulação via medicalização.
Pensar as enfermidades psíquicas a partir de uma perspectiva fenomenológico-existencial, consiste em não mais submeter o singular ao universal. Com isso, não se quer dizer que o plural ou o universal seja abandonado, mas que o universal fique submetido ao singular. Assim, compreende-se o homem nas suas diferentes possibilidades de ser, não mais o tomando como um objeto que só pode se dar da forma ditada pelos padrões culturais, sem deixar de considerar as enfermidades propriamente ditas que, pela exacerbação de apenas uma possibilidade, consistindo numa restrição de sentido, levam esse homem a um sofrimento extremo que pode apontar para a necessidade urgente de ação médica interventiva.

O risco está, portanto, no reducionismo, seja dos modos de ser a uma patologização entre aquelas descritas nos manuais ou das enfermidades psíquicas apenas a diferenças das expressões individuais. Para que não se incorra em nenhuma dessas reduções, faz-se necessário buscar o sentido original, de modo a libertar o pensamento de qualquer complicação ou simplificação excessiva. 
Para buscar o sentido original das enfermidades psíquicas vai-se ao encontro do pensamento filosófico existencial de Kierkegaard nas suas obras "Diário de um sedutor" e "Temor e Tremor", onde histórias concretas são relatadas, e proceder-se-á à análise existencial desses personagens.

No intuito de ilustrar o pensamento original com relação ao modo de ser do homem, primeiramente descreverse-ão os personagens Johannes - o "Sedutor", encontrado no texto "Diário de um sedutor", publicado no livro $\mathrm{Ou}$ $\mathrm{Ou}$, primeiro volume, escrito por Kierkegaard, editado pelo pseudônimo Vítor Eremita e assinado pelo pseudônimo "A" em 1843.

A história trata das estratégias de um jovem sedutor cujo único sentido da sua vida é a conquista. Na descrição detalhada de suas estratégias de sedução vai aparecendo toda a sua indiferença com relação aos sentimentos alheios, bem como o prazer intenso no sucesso de cada artimanha.

Logo no início da sua obra, Kierkegaard, por intermédio do pseudônimo "A" descreve, psicologicamente, o protagonista:

A sua vida foi uma experiência constante para realizar a tarefa de viver poeticamente. Dono de uma habilidade extremamente evoluída para descobrir o que de atraente existe na vida, soube encontrá-lo e, tendo-o descoberto, soube sempre traduzir o que vivera com uma veia quase poética (Kierkegaard, 2002, p. 15).

Em "Desespero humano", Kierkegaard estrutura uma verdadeira obra psicológica. Refere-se ao eu e a sua constituição. $\mathrm{O}$ eu se constitui na dialética paradoxal do finito e infinito, necessários e possíveis e eterno e temporal. Afirma que a queda se dá pela carência de um desses termos, referindo-se à perda do eu no infinito por carência de finito:

Muitos homens que corporalmente vivem no mundo da realidade, não pertencem, no entanto, a ele, senão aquele outro distante. O fato de se perderem na distância e desaparecerem quase por completo da cena real podem ser explicados tanto por razões de saúde, quanto de doença (Kierkegaard, 1988, pp. 33-34).

Em Johannes, a constituição do eu se dava no desespero de infinito por carência de finito, e que nele se tratava de uma doença. Isto fica explicitado nos seguintes trechos: "Este homem não pertencia à realidade, se bem que mantinha muitas relações com ela" (Kierkegaard, 2002, p. 15). Percebia o mundo da realidade desestimulante, mas estimulava-se apenas com alguns momentos fugazes. Escapava da realidade não por sucumbir frente a ela, mas, por sua força e determinação, a realidade era muito pouco para ele. E essa força e determinação consistiam em sua enfermidade, pois quando caia no finito:
Logo que a realidade perdia para si mesmo o poder estimulante, ficava desarmado e este estado de abatimento constituía seu mal específico. No instante mesmo do estímulo tinha consciência do seu estado e nessa consciência radicava o mal que havia em sua vida (Kierkegaard, 1988, p. 34).

A personalidade de Johannes se constituía no desespero dos possíveis por carência de necessários. Para ele, só havia possibilidades a conquistar, e, para tanto, elaborava estratégias, manipulava o outro, enfim, o tempo todo jogava e, pouco a pouco, pacientemente, tudo para si e seu prazer era possível. Seu necessário consistia, silenciosamente, na manutenção do prazer, algo do qual não conseguia prescindir.

Ansiar para si apenas possíveis implica poder olhar, somente, para si mesmo. Kierkegaard descreve Johannes como o protótipo do estético e remete ao aspecto egoísta desse estágio, definido por José Maria Valverde (Kierkegaard, 1988) como narcisismo, ao afirmar que o protagonista do romance não é dominado pela angústia e sim por um profundo narcisismo.

Em uma vivência de subjetivismo extremo e com a vontade exercida no presente imediato, esse homem torna-se determinado pelos impulsos, pela indiferença frente ao outro.

Sem interioridade e pleno de exterioridade, Johannes funda o sentido de sua vida nas sensações sob o domínio do prazer. Segundo o escritor: "o prazer formava-se na finalidade de toda a sua vida" (Kierkegaard, 2002, p. 15). Johannes desfrutava principalmente de dois prazeres na sua vida:

1. "Desfrutava pessoalmente a sua estética, após o que gozava esteticamente a sua personalidade". Gozava, então, egoisticamente, ele mesmo, o que a realidade lhe oferecia, assim como aquilo que fertilizava essa realidade; no segundo caso, a sua personalidade deixava de atuar, e gozava a situação, e a si próprio na situação;

2. Deleitava-se na circunstância poética da realidade, "e que retomava sob o formato de reflexão poética" (Kierkegaard, 2002, pp. 15-16).

O prazer não estava presente apenas na conquista, mas em toda ação de articular, de desenvolver as táticas, a fim de influenciar e determinar os sentimentos de uma mulher, que ele escolhe como vítima, justamente por suas características de inocência e auto-estima. Nessas características, encontra o maior prazer em seduzir e em conduzi-la à direção desejada por ele.

Heidegger (1989) refere-se ao cuidado, ao modo da preocupação que se dá na relação Dasein-Dasein, e ao modo da ocupação Dasein-objetos. Johannes relacionava-se com essas pessoas - Cordélia, Eduardo e a tia de Cordélia como se fossem objetos, que ele manipulava ao seu bemquerer. Descreve, por meio do protagonista, a etapa estética em sua frivolidade e com ausência de compromisso. A sedução é calculada: pode-se constatar como Johannes 
toma Cordélia como se se tratasse de um objeto de prazer que o atrai até mesmo no ato de conquistar: "Nada de impaciência, nada de voracidade, tudo gozarei atraindo lentamente. Ela é o que elegi, e sem dúvida a conquistarei” (Kierkegaard, 1988, p. 50).

No desespero de eterno por carência de temporal, Johannes desejava tornar eterno o seu prazer, para tanto queria alargar, tanto quanto possível, o presente. Essa tentativa de eternizar o presente fica evidente no seguinte trecho:

Por decorrência, o seu diário não é uma exatidão histórica, nem é simplesmente uma narrativa, não foi redigido no modo indicativo, mas sim no conjuntivo. Embora contenha os pormenores naturalmente anotados após terem sido vividos, às vezes, mesmo bastante tempo depois, a narrativa dá, muitas vezes, a impressão de que tudo ocorre naquele mesmo momento, sendo a vida dramática de tal forma intensa que, por vezes, se diria que tudo transcorre diante dos nossos olhos" (Kierkegaard, 2002, p. 15).

À medida que a busca do imediato eternizado fracassa, o esteta torna-se melancólico e aprisionado num grande vazio. A procura do instante efêmero, que nunca se realiza, torna-se melancólica, e, em desespero, abre-se a possibilidade que se dê o salto para o estádio posterior.

Algumas vezes tem-se a nítida impressão de que Johannes acredita que ajuda Cordélia a se tornar mais forte e que na verdade faz-lhe um favor: "É com maior firmeza e continência que eu próprio velo para que se possa desenvolver tudo o que nela existe, toda a riqueza de sua natureza divina" (Kierkegaard, 2002, p. 92).

A condição de esteta é reconhecida por Johannes a seguir:

Eu sou um esteta, um erótico, que apreendeu a natureza do amor, a sua essência, que crê no amor e o conhece a fundo, e apenas me reservo à opinião muito pessoal de que uma aventura galante só dura, quando muito, seis meses, e que tudo chegou ao fim quando alcançam os últimos favores. Sei tudo isto, mas sei também que o prazer imaginável é ser amado, ser amado acima de tudo. Introduzir-se com um sonho na imaginação de uma jovem é uma arte, sair dela, uma obra prima (Kierkegaard, 2002, pp. 76-77).

Em uma análise baseada nas descrições clínicas e diretrizes diagnósticas da CID-10, Johannes obteria a classificação F-60. 2 - Transtorno de personalidade anti-social:

Transtorno de personalidade, usualmente vindo de atenção por uma disparidade flagrante entre o comportamento e as normas sociais predominantes, e caracterizado por:

a) Indiferença sensível pelos sentimentos alheios;

b) Atitude flagrante e persistente de irresponsabilidade e desrespeito por normas, regras e obrigações sociais;

c) Incapacidade de manter relacionamentos, embora não haja incapacidade de estabelecê-los;

d) Muito baixa tolerância à frustração e baixo limiar para descarga de agressão, incluindo violência; e) Incapacidade de experimentar culpa e de aprender com a experiência, particularmente punição;

f) Propensão marcante para culpar os outros ou para oferecer racionalizações plausíveis para o comportamento que levou o paciente a conflito com a sociedade (Organização Mundial de Saúde, 1993, pp. 199-200).

Não há dúvida de que Johannes apresentava muito desses comportamentos descritos acima. A questão implica que, considerando o universal, coloca-se em plano secundário a singularidade. Além do quê, a clínica que parte da representação do sujeito passa a compreendê-lo a partir daquilo que representa. Aquele homem, nesse caso, seria um psicopata com os seguintes aspectos presentes em sua personalidade, que apontam para a positividade de uma psicopatia: alegria excessiva, excitação e irritabilidade, interesse por tudo, visão otimista da realização do seu projeto, contato manipulador com tudo e com todos, ausência de sentimento de culpa, ausência de afetividade nas relações, crença de que todo o sofrimento que causava ao outro, no final das contas, seria para seu bem, o imenso prazer em dominar o outro.

Em uma perspectiva fenomenológico-existencial, não há abandono do universal, no entanto o interesse é o singular, onde não cabe apreender a experiência de Johannes como uma patologia pelas possibilidades que se apresentam, mas por aquelas que estão ausentes, aquelas das quais o homem doente está privado. Johannes estava privado de viver conforme outras possibilidades que não fossem a extremamente prazerosa. Nisso consistia a sua queda.

Doença, como escassez ou ausência de movimento, consiste na tentativa de paralisar, "queda", seja no real, na ação ou no imaginário. Seja nos necessários, seja nos possíveis, seja no eterno seja no temporal, na impessoalidade ou no pessoal. Johannes, com desespero de infinito, de possíveis e do eterno, carecia de finito, de necessários e do temporal. Aí reside a sua doença mortal: o desespero.

Em outra obra, "Temor e Tremor", publicada em 7 de outubro de 1843 sob o pseudônimo de Johannes de Silentio, Soren Kierkegaard inclina-se sobre a história de Abrahão, esposo de Sara e pai de Isaque. Acompanha esse homem, seu filho Isaque e seu servo a caminho do Monte Morija, onde Abrahão, atendendo ao pedido de Deus, oferecerá seu filho em sacrifício. $O$ autor almeja compreender esse ato de Abrãao que, tendo sido pai tardio de um único filho, dispõe-se a oferecê-lo em holocausto, respondendo à solicitação que lhe chega da parte de Deus.

Acompanhando a saga de Abrahão, o autor pondera acerca da possibilidade da entrega ao singular. Para Kierkegaard, todo existente alcança a si mesmo quando se entrega ao absoluto. Nesse livro, irá dissertar sobre o momento em que o homem se entrega, pela fé, ao clamor mais pungente de si mesmo, ao que lhe é mais próprio: o finito, o temporal, enfim, a realidade. 
Detém-se a refletir e a extasiar-se com esse momento, o momento da decisão, quando as leis do mundo perdem o sentido e o homem se permite matar seu próprio filho, quando os desejos e paixões são rechaçados e o homem abre mão do prazer e do orgulho de ter sido finalmente pai e do desejo de vê-lo crescer e dar-lhe netos, e escolhe ouvir uma voz que clama, que lhe pede o filho em sacrifício.

Pondera, então, que uma escolha dessa natureza não poderia ocorrer de forma racional, que só seria possível como um ato absurdo, incompreensível, fundado em algo que transcendesse a compreensão compartilhada, e esse algo ele diz ser a fé. Explica que o homem da fé deixa-se mover pela paixão. Não se dispersa, não se justifica nem se contradiz, pois contradizer-se pertence ao racional. Numa escolha fundada na razão vive-se no "inverossímil, inesperado, imprevisto", no injusto, no certo ou errado, onde aquele que escolhe se convence da "impossibilidade segundo o alcance humano”. Mas Abrahão, o cavaleiro da fé, na resignação infinita, sustenta a impossibilidade perante o mundo, aceita a perda do filho, realizando sua tarefa em paz e repouso no finito, no real, crendo no absurdo. "O paradoxo da fé não pode reduzir-se a nenhum raciocínio, porque a fé começa precisamente onde acaba a razão" (Kierkegaard, 1990, p. 71).

Ao debruçar-se sobre esse fato particular da vida do ancião, sua entrega convicta ao pedido de Deus para que sacrifique seu único filho, o filho da promessa, Kierkegaard quer pensar a resignação e a capacidade de assumir atitudes que contrariem quaisquer referências que não sejam os ditames divinos. Para o autor dinamarquês, a voz de Deus é a voz que clama em cada um de nós para que tenhamos coragem de nos tornarmos transparentes a nós mesmos, de assumirmos de forma radical uma posição singular na vida.

Kierkegaard adverte para o apelo que as coisas do mundo exercem sobre a consciência, seja anunciando caminhos mais fáceis de obtenção infinita de prazer, e estaríamos no estádio estético, seja apelando para que sigamos os ditames do social, as regras do bem-viver consensual, e estaríamos no estádio ético, afirmando que esses apelos dispersam e adiam a realização do movimento da fé, confundindo o cavaleiro acerca de si mesmo. Nesse sentido, o cavaleiro sofre uma constante prova, pois pode a qualquer momento regressar de sua decisão, arrepender-se, e encontrará suporte no seio do geral, do todo mundo, ficando fora do paradoxo. No entanto, como indivíduo singular e optando por viver dentro do paradoxo, não pode pedir a ninguém que o ajude ou o ilumine. Sabe que tamanha grandeza é acessível a todos e a cada um, mas somente como indivíduo, singular e solitário.

Pretendendo tornar mais claro esse momento psicológico de entrega ao que é mais próprio, Kierkegaard contrapõe dois personagens: o herói e o cavaleiro da fé, considerando que ambos são capazes de se sacrificarem. $\mathrm{O}$ herói se entrega a uma saga, pelo amor de sua princesa; o cavaleiro da fé vive sua saga pelo amor de Deus; o herói encontra suporte no ético, na lógica compartilhada, podendo ser ajudado, uma vez que pode ser compreendido por seus contemporâneos; o cavaleiro da fé, Abrahão, esse se encontra solitário, pois sua saga não faz sentido para outros homens. Aquele que sacrifica seu filho como pagamento por uma promessa ou bênção concedida está no estádio ético, pois pode compartilhar sua ação e sua dor com outros homens. $\mathrm{O}$ cavaleiro da fé, aquele que responde secretamente a um apelo divino, não pode compartilhar isto com ninguém e nem tem em quem encontrar suporte, está só, e cumpre sua saga em nome do absurdo.

Afirma Le Blanc: "A fé instaura entre o eu e o mundo, entre o eu e ele mesmo, uma relação de estabilidade que apaga angústia e desespero, apenas pelo princípio de que para Deus tudo é possível” (2003, p. 90).

A fé surge, então, como possibilidade de estabilidade naquilo que constituiu o homem: o desespero. $\mathrm{O}$ último estádio antes dela, segundo Kierkegaard, é a resignação infinita, a capacidade de reconhecer-se e colocar-se de forma absoluta em sua situação. O humor surge como a atitude psicológica nesse momento, quando o homem pode rir de si mesmo, reconhecendo-se inteiramente em sua situação, transparecendo-se para si próprio. O cavaleiro da fé renunciou à compreensão como forma de sair do desespero. Entrega-se ao irracional, ao absoluto. Vê a si mesmo como parte de um projeto divino e, consciente de sua situação, entrega-se a esse caminho.

O cavaleiro da fé

converte em resignação infinita a profunda melancolia da vida; conhece a felicidade do infinito; experimentou a dor da total renúncia àquilo que mais ama no mundo - e, no entanto, não mostra indício de sofrer inquietação ou temor, diverte-se com tal tranqüilidade, que, parece, nada há de mais certo que este mundo finito. Resignou-se infinitamente a tudo para tudo recuperar pelo absurdo (Kierkegaard, 1990, p. 56).

Abrahão enfrenta o desespero por intermédio da fé nos possíveis. Em sua liberdade, vê além da objetividade da razão, superando o desespero. Escreve Kierkegaard, em Desespero humano (1961, p. 224): "formulamos o estado dum eu do qual o desespero está totalmente ausente: na sua relação com ele próprio, e querendo ser ele próprio, o eu mergulha através da sua própria transparência até o poder que o criou. E essa fórmula é, por sua vez, como tantas vezes o lembramos, a definição da fé”.

Para Kierkegaard,

o cavaleiro deve ter a força de concentrar toda a substância da vida e todo o significado da realidade em um único desejo. No caso de o não conseguir, a alma encontra-se desde o princípio dispersa no múltiplo e jamais chegará a realizar o movimento. Na falta de tal concentração, correrá incessantemente atrás dos problemas da vida, sem nunca encontrar a eternidade. (Kierkegaard, 1990, p. 58). 
Abrahão, o cavaleiro da fé, não se esquece por que o que o orienta não é a memória, e sim a lembrança, que traz em si a unidade, e por isso não se contradiz. Reconhece, aceita, enfim, revalida as necessidades da realidade, as inevitáveis conseqüências, e não se decepciona. Alcança a resignação infinita, a qual "implica paz e repouso", reconciliando-se com a vida tal como ela é, não mais elocubrando sobre como ela deveria ser. Não importam os acontecimentos da realidade, pois o cavaleiro da fé resigna-se às necessidades da realidade: orgulho, motivos de riso, inserção de terceiros, desprazeres, anseios, adeuses, encontros e desencontros, próprios do herói, perdem importância para o cavaleiro da fé, pois este descobriu o grande segredo que é "dever-nos bastar-nos a nós próprios mesmo quando amamos".

O cavaleiro da fé não precisa da intervenção do finito, do real para favorecer o crescimento do seu amor. Não precisa que as coisas se dêem conforme gostaria. Realizou o salto para o infinito, onde a realidade perdeu importância, não confunde mais. O cavaleiro da fé, em sua ação, salta para o absurdo, só atingível pela fé.

Em uma análise baseada nas descrições clínicas e diretrizes diagnósticas da CID-10, Abrahão obteria a classificação F-20.0, Esquizofrenia paranóide, com as seguintes descrições:

a- delírios de perseguição, referência, ascendência importante, missão especial ${ }^{1}$, mudanças corporais ou ciúmes.

b- vozes alucinatórias, que ameaçam o paciente ou lhe dão ordens, ou alucinações auditivas sem conteúdo verbal, tais como assobio, zunido ou riso;

c- alucinações olfativas ou gustativas, sensações sexuais ou outras corporais, alucinações visuais podem ocorrer porém raramente são predominantes. (Organização Mundial de Saúde, 1993, p. 88)

Abrahão ouvia a voz de Deus, ninguém mais podia ouvi-la, e via Deus, sentia sua presença e conversava com ele, sem poder compartilhar essa realidade, pois reconhecia que ninguém o aprovaria. É a coragem de responder em ação a esse chamado que lhe proporciona a experiência de, transcendendo a toda lógica, encontrar seu próprio sentido. Numa perspectiva fenomenológicoexistencial, o desafio está em compreender o outro em seus referenciais, em abster-se das referências universais e assim poder apreender aquele que sofre em suas referências singulares. O sentido de uma vida é sempre um sentido singular, que se realiza inevitavelmente no geral, no universal. Esse modo de ser é caracterizado por Kierkegaard como o estádio religioso, no qual o singular e o universal se religam numa existência concreta em que os elementos se congregam de forma a fazer sentido, promovendo a experiência do encontro do homem consigo mesmo, com seus semelhantes e com as forças que o transcendem. Na vivência cotidiana o apelo é realizar-se como paradoxo, como espírito que se constitui enquanto

Grifos das autoras. conjunto de fatores que tensionam o existente e o convidam a realizar-se no instante concreto. Sabendo-se temporal, o homem pode pensar-se eterno mediante a projeção de sua existência para o futuro; sabendo-se limitado, o homem pode ampliar suas limitações numa atitude de abertura de novas possibilidades; sabendo-se finito, pode imaginar-se além da concretude dessa finitude, imaginando o inimaginável para si.

\section{Considerações Finais}

A ciência estabeleceu-se a partir de uma exigência de explicar a realidade através de um sistema lógico e universal, dessa forma, tornando possível a previsibilidade, o controle, as alterações da realidade toda vez que ela se mostrasse desviante de um padrão estabelecido $a$ priori. A partir daí surgiu a psicopatologia atendendo à exigência de logicidade, e a psiquiatria, como a especialização técnica habilitada a prever, controlar e alterar os comportamentos humanos que se afastassem dos padrões ditos normais. Assim, as expressões singulares são capturadas pelas descrições universais. Ou seja, o singular desaparece e o homem passa a ser visto pela categoria que lhe é dada.

A partir das descrições universais, sem dúvida, Johannes, o sedutor, se enquadraria na categoria de Transtorno de Personalidade Anti-social, já que atenderia à lógica descritiva, o que o encaminharia ao tratamento adequado. Abrahão receberia o diagnóstico de Esquizofrenia Paranóide, uma vez que, na descrição de seu comportamento, confirmam-se as vozes alucinatórias que lhe dão ordens, conferindo-lhe uma missão especial. Não mais, ao olhar Abrahão, se veria a sua singularidade, pois agora, ao vê-lo, passa-se a encontrar um esquizofrênico paranóide.

Esses mesmos homens, ao serem vistos por aquele que olha a singularidade tal como ela se dá a ver, se deslocaria dessa visada da ciência para poder enxergar aquele que se apresenta ao seu modo.

Johannes apresenta-se como aquele que desfruta continuamente do prazer de constatar a eficácia de suas estratégias, e a isso dedica toda energia de sua vida. Em uma insensibilidade extrema, torna-se indiferente ao sofrimento que pode provocar no outro. Esse outro que não é nada mais do que uma peça que ele maneja para vencer o jogo, o que fica claro em suas palavras: "Este ano, no entanto, não aumentei minha coleção de casos interessantes. Esta moça me mantém demasiadamente ocupado. Meus ganhos serão pequenos, mas me consolo por estar na pista do negócio do ano" (Kierkegaard, 1988, p. 68).

Abrahão, o personagem de Temor e Tremor, apresentase como aquele que conseguiu a entrega total ao absurdo. Constitui-se como homem que lutou contra o mundo e triunfou sobre o mundo, grande também porque lutou e triunfou contra si mesmo e, mais ainda, lutou e triunfou contra Deus, porque acreditou. Abrahão foi o maior 
de todos: "grande pela energia cuja força é debilidade, pelo saber cujo segredo é loucura, pela esperança cuja forma é demência, pelo amor que é ódio de si mesmo" (Kierkegaard, 1990, p. 31).

Para Kierkegaard, "o homem de nosso tempo, isolado do mundo natural pela adesão à técnica e afastado de Deus, é uma pessoa 'deslocada', indivíduo com quem o mundo tem de contar e cuja psicologia não acaba de compreender totalmente todavia”. (Kiekegaard, 2002, p. 154).

\section{Referências Bibliográficas}

Heidegger, M. (1927/1989). Ser e tempo. Petrópolis: Vozes.

Kierkegaard, S. A. (1843/1988). Diario de un sedutor. Barcelona: Ediciones Destino.

Kierkegaard, S. A. (1843/1990). Temor e tremor. Lisboa: Guimarães editores.

Kierkegaard, S. A. (1843/2002) Diário de um sedutor. São Paulo: Editora Martin Claret.

Kierkegaard, S. A. (1849/1961). O desespero humano, doença até a morte. Porto: Livraria Tavares Martins.

Kierkegaard, S. A. (1859/1988). Mi punto de vista. Madrid: Aguilar.

Le Blanc, C. (1998/2003). Kierkegaard. São Paulo: Estação Liberdade.

Organização Mundial de Saúde (1993). Classificação internacional das doenças (CID-10), Porto Alegre: Artes Médicas.

Ana Maria Lopez Calvo de Feijoo - Doutora em Psicologia pela Universidade Federal do Rio de Janeiro, Mestre em Psicologia da Personalidade pela FGV/ISOP, Especialista em Psicologia Clínica pelo Instituto de Psicologia Fenomenológico-Existencial do Rio de Janeiro (IFEN), Sócia Fundadora, Presidente, Responsável Técnica, Professora, Supervisora e Orientadora de monografia do Curso de Especialização em Psicologia Clínica do Instituto de Psicologia Fenomenológico-Existencial do Rio de Janeiro - IFEN e Professora Adjunta da Universidade Estadual do Rio de Janeiro (UERJ). E-mail: <ifen@ifen.com.br>

Myriam Moreira Protasio - Especialista em Psicologia Clínica pelo Instituto de Psicologia Fenomenológico-Existencial do Rio de Janeiro (IFEN), Sócia Fundadora, Professora, Supervisora e Orientadora de Monografias do Curso de Especialização em Psicologia Clínica do IFEN. E-mail: <ifen@ifen.com.br>

Recebido em 25.05 .08

Aceito em 15.06.08 